\title{
COMMENTARY
}

\section{Noninvasive surrogates of intracranial pressure: another piece added with magnetic resonance imaging of the cerebrospinal fluid thickness surrounding the optic nerve}

Thomas Geeraerts

See related research by Xie et al., http://ccforum.com/content/17/4/R162
We have known for years that the prognosis in neurocritical patients (traumatic brain injury or stroke) is affected by the incidence of raised ICP, and is particularly affected by the time spent with ICP $>25 \mathrm{mmHg}$ [6]. In other medical conditions, however, invasive ICP is rarely measured. Having a noninvasive estimate of ICP is certainly of great interest to detect patients at risk of raised ICP and to initiate specific treatments aiming at decreasing ICP, and/or to decide to monitor ICP invasively.

In the absence of obstruction in the cerebrospinal fluid (CSF) circulation, the subarachnoid space surrounding the optic nerve is submitted to the same pressure as the intracranial compartment. Owing to the cul-de-sac anatomy of the optic nerve, CSF can accumulate in the retro-orbital part of the optic nerve, and the sheath can inflate in the presence of raised ICP [7]. Several publications have shown than the optic nerve sheath diameter measured using ultrasound [8-10] or MRI [11,12] correlates well with invasive ICP.

In an elegant study, Xie and colleagues have shown that the CSF width surrounding the optic nerve measured using a simple T2-weighted fast-recovery fast-spin echo fat-suppressed sequence correlates well with lumbar CSF pressure in 72 patients with various neurological conditions (CSF hypotension, meningitis, multiple sclerosis, and so forth) [13]. Very similar results showing that the MRI optic nerve sheath, but not the optic nerve itself, correlated well with invasive ICP in comatose traumatic brain injury patients have been published previously in Critical Care [11].

Using a stepwise multivariate linear regression analysis, Xie and colleagues have developed a relatively simple formula based on the CSF width surrounding the 
optic nerve, body mass index, and blood pressure to predict ICP noninvasively [13]. In the ICP range from 3 to $26 \mathrm{mmHg}$, CSF widths $3 \mathrm{~mm}, 9 \mathrm{~mm}$ or $15 \mathrm{~mm}$ behind the retina significantly correlated with the lumbar CSF opening pressure $\left(r^{2}=0.82\right.$ to 0.88$)$ We must, however, note that significant raised ICP (ICP $>20 \mathrm{mmHg}$ ) was only present in eight of the 72 patients. Moreover, lumbar CSF pressure and MRI were performed with a 24hour delay. We should also highlight that the relationship between optic nerve sheath enlargement and ICP may not be linear. Hansen and colleagues have clearly shown in an experimental study that a plateau can be reached with a maximum enlargement of the sheath occurring for high ICP values (above 35 to $40 \mathrm{mmHg}$ ), and that capability for retraction of the sheath can be altered after exposing the optic nerve trabecula to high pressure and distension [14]. These limitations of the study should be taken into consideration before generalisation of these results in ICU patients with significant raised ICP.

A major interest of the Beijing Intracranial and Intraocular Pressure Study Group is that body mass index has been considered in the prediction model [13]. Anatomy can obviously affect the size of the optic nerve and its sheath. However, normative data of the optic nerve complex, considering the age and the height of the subject, are lacking. Determining these data should be probably be an initial step in the process of studying the possible utilization of the optic nerve CSF width to predict raised ICP.

The T2-weighted fat-suppressed MRI sequence lasts less than 5 minutes and is considered a standard sequence. Moreover, measuring the CSF width takes less than 1 minute. Considering the very interesting results from the Beijing Intracranial and Intraocular Pressure Study Group and the simplicity of optic nerve width measurement, we could wonder whether this parameter should be systematically measured when MRI is performed in comatose patients. This measurement could offer the possibility to detect raised ICP using a simple formula taking into consideration the optic nerve width, the body mass index and mean arterial blood pressure. Early detection of raised ICP based on MRI is certainly of great interest to initiate specific treatments and to refer patients to a specialised critical care unit.

\section{References}

1. Ware AJ, D'Agostino AN, Combes B: Cerebral edema: a major complication of massive hepatic necrosis. Gastroenterology 1971, 61:877-884.

2. Han MK, Hyzy R: Advances in critical care management of hepatic failure and insufficiency. Crit Care Med 2006, 34:S225-S231.

3. Quagliarello V, Scheld WM: Bacterial meningitis: pathogenesis, pathophysiology, and progress. N Engl J Med 1992, 327:864-872.

4. Cipolla MJ: Cerebrovascular function in pregnancy and eclampsia. Hypertension 2007, 50:14-24.

5. Bergman R, Tjan DH, Adriaanse MW, van Vugt $R$, van Zanten AR: Unexpected fatal neurological deterioration after sucessful cardiopulmonary resuscitation and therapeutic hypothermia. Resuscitation 2008, 76:142-145.

6. Chesnut RM, Marshall LF, Klauber MR, Blunt BA, Baldwin N, Eisenberg HM, Jane JA, Marmarou A, Foulkes MA: The role of secondary brain injury in determining outcome from severe head injury. J Trauma 1993, 34:216222

7. Hayreh SS: Pathogenesis of oedema of the optic disc (papilloedema). A preliminary report. Br J Ophthalmol 1964, 48:522-543.

8. Geeraerts T, Launey Y, Martin L, Pottecher J, Vigue B, Duranteau J, Benhamou D: Ultrasonography of the optic nerve sheath may be useful for detecting raised intracranial pressure after severe brain injury. Intensive Care Med 2007, 33:1704-1711.

9. Dubourg J, Javouhey E, Geeraerts T, Messerer M, Kassai B: Ultrasonography of optic nerve sheath diameter for detection of raised intracranial pressure: a systematic review and meta-analysis. Intensive Care Med 2011, 37:1059-1068

10. Soldatos T, Karakitsos D, Chatzimichail K, Papathanasiou M, Gouliamos A, Karabinis A: Optic nerve sonography in the diagnostic evaluation of adult brain injury. Crit Care 2008, 12:R67.

11. Geeraerts T, Newcombe VF, Coles JP, Abate MG, Perkes IE, Hutchinson PJ, Outtrim JG, Chatfield DA, Menon DK: Use of T2-weighted magnetic resonance imaging of the optic nerve sheath to detect raised intracranial pressure. Crit Care 2008, 12:R114.

12. Watanabe A, Kinouchi H, Horikoshi T, Uchida M, Ishigame K: Effect of intracranial pressure on the diameter of the optic nerve sheath. $J$ Neurosurg 2008, 109:255-258.

13. Xie X, Zhang X, Fu J, Wang H, Jonas JB, Peng X, Tian G, Xian J, Ritch R, Li L, Kang Z, Zhang S, Yang D, Wang N, Beijing iCOP Study Group: Noninvasive intracranial pressure estimation by orbital subarachnoid space measurement: the Beijing Intracranial and Intraocular Pressure (iCOP) study. Crit Care 2013, 17:R162.

14. Hansen HC, Lagreze W, Krueger O, Helmke K: Dependence of the optic nerve sheath diameter on acutely applied subarachnoidal pressure - an experimental ultrasound study. Acta Ophthalmol 2011, 89:e528-e532.

doi:10.1186/1364-8535-17-187

Cite this article as: Geeraerts: Noninvasive surrogates of intracranial pressure: another piece added with magnetic resonance imaging of the cerebrospinal fluid thickness surrounding the optic nerve. Critical Care 2013, 17:187

\author{
Abbreviations \\ CSF: Cerebrospinal fluid; ICP: Intracranial pressure; MRI: Magnetic resonance \\ imaging.
}

